\title{
Development of a healthy biscuit: an alternative approach to biscuit manufacture
}

\author{
WJ Boobier, JS Baker* and B Davies
}

\author{
Address: Health and Exercise Science Research Unit, School of Applied Sciences, University of Glamorgan, Pontypridd, CF37 1DL, UK \\ Email: WJ Boobier - wboobier@glam.ac.uk; JS Baker* - jsbaker@glam.ac.uk; B Davies - bdavies1@glam.ac.uk \\ * Corresponding author
}

Published: 15 March 2006

Nutrition Journal2006, 5:7 doi:10.1/86/1475-289/-5-7

This article is available from: http://www.nutritionj.com/content/5/I/7

(C) 2006Boobier et al; licensee BioMed Central Ltd.

This is an Open Access article distributed under the terms of the Creative Commons Attribution License (http://creativecommons.org/licenses/by/2.0), which permits unrestricted use, distribution, and reproduction in any medium, provided the original work is properly cited.
Received: 17 November 2005

Accepted: 15 March 2006

\begin{abstract}
Objective: Obesity $(\mathrm{BMI}>30)$ and related health problems, including coronary heart disease (CHD), is without question a public health concern. The purpose of this study was to modify a traditional biscuit by the addition of vitamin $B_{6}$, vitamin $B_{12}$, Folic Acid, Vitamin $C$ and Prebiotic fibre, while reducing salt and sugar.

Design: Development and commercial manufacture of the functional biscuit was carried out in collaboration with a well known and respected biscuit manufacturer of International reputation. The raw materials traditionally referred to as essential in biscuit manufacture, i.e. sugar and fat, were targeted for removal or reduction. In addition, salt was completely removed from the recipe.

Participants: University students of both sexes $(n=25)$ agreed to act as subjects for the study. Ethical approval for the study was granted by the University ethics committee. The test was conducted as a single blind crossover design, and the modified and traditional biscuits were presented to the subjects under the same experimental conditions in a random fashion.

Results: No difference was observed between the original and the modified product for taste and consistency $(P>0.05)$. The modified biscuit was acceptable to the consumer in terms of eating quality, flavour and colour. Commercial acceptability was therefore established.

Conclusion: This study has confirmed that traditional high-fat and high-sugar biscuits which are not associated with healthy diets by most consumers can be modified to produce a healthy alternative that can be manufactured under strict commercial conditions.
\end{abstract}

\section{Background}

The UK diet is high in fat, particularly saturated fat, e.g. in 1992 over $40 \%$ of all energy intake was derived from fat, with over 15\% coming from saturated fat alone [1]. The European Economic Community (EEC) nutrition policy goal suggested that only $20-30 \%$ of energy should be derived from fat [2]. There is considerable epidemiological evidence that nutritional intake is related to the risk of coronary heart disease (CHD) $[3,4]$. To reduce the inci- dence of CHD the department of Health has recommended that the proportions of energy derived from total fat should be reduced to $35 \%$, and from saturated fat to $10 \%[1]$.

Also, the replacement of saturated or trans-unsaturated fat with unhydrogenated unsaturated fats is associated with larger reductions in risk factors associated with CHD than replacement by carbohydrate [5]. 
Other dietary changes considered helpful in the fight against coronary heart disease include consumption of a high fibre diet [6], reduction of salt and sugar intake [7-9]. In a study conducted by Pietinen et al., [6] the mean intake of soluble fibre in the diet was 5.4 g.day ${ }^{-1}$ compared to 18.9 g.day $^{-1}$ for insoluble fibre. They reported that an increase in daily soluble fibre by $3 \mathrm{~g}$ reduced the risk of coronary death by $27 \%$. Dietary sodium reduction has been recommended to reduce hypertension and cardiovascular disease mortality and morbidity [9]. Large amounts of sucrose, or other refined carbohydrate, cause an increase in lipid triglyceride, an increase not associated with complex-starch intake [8]. Biscuits are a popular food eaten by both children and adults; however, they are typically high in the materials (fat and sugar) that make them "unhealthy". In the manufacture of biscuit dough, it is traditional to use fat which is semi-solid at room temperature e.g. palm oil which contains $50 \%$ saturated fatty acids. In addition, the biscuit market is dominated by short dough biscuits having fat levels in excess of $20 \%$ [10]. Biscuits are therefore an obvious choice when consumers are asked to reduce their total fat intake. The concluding paragraph of the Diet and Heart Disease report [11] states that high fat bakery products should be reduced in the diet. In addition, biscuits have previously been highlighted in a report by Willet $e t$ al., [12] as being significantly associated with an increased risk of CHD.

The development of a commercially viable biscuit attractive to children and adults that will have a significant reduction in fat and sugar, with fewer calories and contain nutrients designed to reduce the risk of coronary heart disease is highly desirable.

The purpose of this study is to describe the development of a healthy biscuit (functional food) with low moisture, long shelf life that has commercial viability, has had sodium chloride reduced and pre-biotic fibre, $\mathrm{B} 6, \mathrm{~B}_{12}$ folic acid and vitamin $\mathrm{C}$ added.

\section{Functional food}

A food can be regarded as functional if it is satisfactorily demonstrated to beneficially affect one or more target functions in the body, beyond adequate nutrition, in a way that improves health and well being or reduces the risk of Disease $[13,14]$. The term functional food was first used in Japan [15], and Japan has been active in the development of this type of product since the early 1980's.

Research to date has focused on several factors that contribute to the health status of individuals. This study has focused attention on the modification of a standard biscuit by the addition of vitamin $\mathrm{B}_{6}$, vitamin $\mathrm{B}_{12}$, Folic Acid, Vitamin $\mathrm{C}$ and Prebiotic fibre, while reducing salt and sugar, thereby converting a traditional food product into a functional one.

\section{Vitamin C (ascorbic acid)}

Ascorbic acid (vitamin C, 2,3-didehydro-L-threo-hexonic acid-g-lactone) is an acid derivative of a 6-carbon sugar. The presence of the "diol" grouping at carbons 2- and 3enables the vitamin to act as a powerful reducing agent. It is evident that subjects with acute myocardial infarction have lower plasma vitamin $C$ than control Subjects [1619]. Although there is no universally accepted recommended daily intake of vitamin $\mathrm{C}$, the World Health Organisation recommends a daily intake of $30 \mathrm{mg}$, whereas in the UK the RDA is $60 \mathrm{mg}^{1}$.

\section{Prebiotic fibre (fructo-oligosaccharide)}

A prebiotic is defined as a non digestible food ingredient that beneficially affects the host by selectively stimulating the growth and/or the activity of one or a number of bacteria in the colon that have the potential to improve health $[20,21]$. Prebiotics, most often referred to as nondigestible oligosaccharides, are extracted from natural sources, e.g. Inulin and oligofructose, or synthesised from disaccharides. Actilight ${ }^{\circledast}$, the prebiotic that was used in this study was obtained from sugar beet comprising of one molecule of glucose linked to two, three or four molecules of fructose. Its use in the final product formulation contributed to the dough characteristics and the organoleptic properties of the biscuit.

\section{Vitamin $B_{6}$}

A number of studies have shown biochemical signs of deficiency or inadequacy of vitamin $B_{6}$ in around $10-20 \%$ of apparently healthy people $[22,23]$. This may be a factor in the development of atherosclerosis, a result of impaired metabolism of methionine and raised circulating levels of homocysteine $[22,23]$. Reference nutrient intakes (RNIs) are based on 15-16 $\mu \mathrm{g}^{-\mathrm{g}^{-1}}$ of protein per day. At average intakes of $100 \mathrm{~g}$ protein per day this gives an RNI of 1.5$1.6 \mathrm{mg}$ of vitamin $\mathrm{B}_{6}$. Average intakes in Britain are between $20-30 \mu \mathrm{g} \cdot \mathrm{g}^{-1}$ protein ${ }^{23}$.

\section{Vitamin $B_{12}$}

The current RNI for vitamin $B_{12}$ is $1.5 \mu \mathrm{g}_{\text {day }}{ }^{-1}$ for males and females 15 to $50+$ years [1]. The addition of Vitamin $\mathrm{B}_{12}$ in the modified biscuit follows the recommendations of several authors [22-24], who observed elevated homocysteine concentrations as a result of impaired vitamin $B_{12}$ status which has been implicated as a cause of premature cardiovascular disease.

\section{Folate (folic acid)}

Folic acid is involved in a number of single carbon transfer reactions, e.g. in the synthesis of methionine [25], the metabolism of which results in the production of homo- 
Table I: Nutritional Information for the Standard and Modified Product per $100 \mathrm{~g}$ of mixture. Zero indicates no concentrations of vitamins in the standard product

\begin{tabular}{|c|c|c|c|c|c|}
\hline & \multicolumn{2}{|c|}{ Standard Product } & \multicolumn{3}{|c|}{ Modified Product } \\
\hline Energy & \multicolumn{2}{|c|}{$1869 \mathrm{~kJ} / 448 \mathrm{kcal}$} & \multicolumn{3}{|c|}{$1675 \mathrm{~kJ} / 396 \mathrm{kcal}$} \\
\hline Protein & \multicolumn{2}{|c|}{4.8} & \multicolumn{3}{|c|}{6.0} \\
\hline Carbohydrates & \multicolumn{2}{|c|}{68.8} & \multicolumn{3}{|c|}{77.3} \\
\hline Of which is sugars & \multicolumn{2}{|c|}{32.5} & \multicolumn{3}{|c|}{22.5} \\
\hline Fat & \multicolumn{2}{|c|}{16.7} & \multicolumn{3}{|c|}{7} \\
\hline - saturates & \multicolumn{2}{|c|}{7.4} & \multicolumn{3}{|c|}{3.1} \\
\hline - mono-unsaturates & \multicolumn{2}{|c|}{6.8} & \multicolumn{3}{|c|}{2.42} \\
\hline - poly-unsaturates & \multicolumn{2}{|c|}{1.9} & \multicolumn{3}{|c|}{1.13} \\
\hline Fibre & & & & 3.4 & \\
\hline \multirow[t]{2}{*}{ Sodium } & \multicolumn{2}{|c|}{0.2} & \multicolumn{3}{|c|}{$\begin{array}{l}3.4 \\
0.1\end{array}$} \\
\hline & Per $100 \mathrm{~g}$ & Per biscuit & Per $100 \mathrm{~g}$ & Per biscuit & $\%$ RDA \\
\hline Vitamin C & Zero & Zero & $302 \mathrm{mg}$ & $55 \mathrm{mg}$ & 92 \\
\hline Vitamin $B_{6}$ & Zero & Zero & $55 \mathrm{mg}$ & $2.0 \mathrm{mg}$ & 100 \\
\hline Folic Acid & Zero & Zero & $1900 \mu \mathrm{g}$ & $347 \mu g$ & 174 \\
\hline Vitamin $B_{12}$ & Zero & Zero & $30.0 \mu \mathrm{g}$ & $2.7 \mu g$ & 135 \\
\hline
\end{tabular}

cysteine as an intermediate product. Normal levels of homocysteine for men are around 8-12 micromoles per litre $\left(\mu \mathrm{mol.} \mathrm{l}^{-1}\right)$ and for women normal levels are $6-10$ $\mu$ mol..$^{-1}[26]$. High blood homocysteine is thought to be an independent risk factor for CHD [26-29]. The conventional view is that as an individual regresses into a negative folate balance, there is a reduction in plasma and tissue concentrations. This would be followed by small and eventually large increases in homocysteine levels [30].

Since moderate reduction in folate status results in elevated plasma homocysteine, a relationship between folate status and risk of cardiovascular disease has been established $[29,31]$. Whilst supplements are suitable for those aware of the potential benefit, even following significant publicity, it's clear that only a small minority of people, especially in the poorer socio-economic sector where the risks may be greater, will take beneficial supplements on a regular basis [32]. This has resulted in suggestions that the diet should be fortified with folic acid, and in the USA it is now policy that flour is required by law to be fortified with folic acid.

\section{Methods}

Development and commercial manufacture of the functional biscuit was carried out in collaboration with a well known and respected biscuit manufacturer of International reputation. The raw materials traditionally referred to as essential in biscuit manufacture, i.e. sugar and fat, were targeted for removal or reduction. In addition, salt was completely removed from the recipe. Fat and sugar was substituted for other materials not associated with poor health, and are outlined later. Following initial manufacturing difficulties, which included poor release from the rotary moulder and tailing, sugar and salt was successfully removed from the recipe of the biscuit base and fat was significantly reduced. The final product was produced under strict commercial conditions to confirm manufacturing viability, and then assessed organoleptically to confirm consumer acceptance.

\section{Assessment of the modified product}

As far as the consumer is concerned, the most important part of any product is taste perception and eating qualities. University students of both sexes $(n=25$, with a mean age \pm 1 standard deviation (SD) of $23 \pm 2$ yrs) having read, completed and signed informed consent forms agreed to act as subjects for the study. Ethical approval was granted by the University ethics committee.

The test was conducted as a single blind crossover design, over a four week period, over two testing periods of two weeks duration. The modified and traditional biscuits were presented to the subjects under the same experimental laboratory conditions in a random fashion with one week intervening between trials. Subjects were given two biscuits per day including weekends. Prior to biscuit consumption, all subjects confirmed that they had not eaten for two hours and were asked to swill out their mouths with cool fresh water to enhance taste perception. All testing for all subjects was performed between the hours of 11 and $12 \mathrm{am}$. The experimental environment was kept constant for both conditions and no outside influences were allowed to interfere with the subject's assessments of the products (smells, music, temperature etc). The trial was repeated one week later for a further two weeks following the same experimental conditions. A hedonic scale 0-9 was used to score the biscuits taste, a score of 1 representing "dislike very much" and 9 representing "like very 
much". The participants were asked to comment briefly on the reasons for the responses given for either the modified or standard product.

\section{Statistical analysis and commercial acceptability}

Statistical analysis was performed using computer software (SPSS). A Wilcoxon Matched Pairs Signed Rank NonParametric Test was used to establish the degree of significance between products. Non parametric statistics were used was because of lack of normal data distribution observed following repeated Kolmogorov-Smirnov tests. Significance levels were accepted at $p<0.05$.

\section{Results}

No difference was observed between the original and the modified product in both trials using the hedonic scale ( $p$ $>0.05)$. The values recorded were $7.6 \pm 1$ for the traditional product and $7.4 \pm 0.6$ for the modified biscuit. The modified biscuit was acceptable to the consumer in terms of eating quality, flavour and colour. Commercial acceptability was therefore established. Product texture of the modified biscuit was a little more open than the standard biscuit, which was thought to be desirable in terms of eating quality. Moisture was maintained as target and there were no signs of ovality (distortion of the biscuit following baking). The product was sent through the manufacturing plant and processed at all stages without any problems. Samples were collected for analysis of vitamin content, other nutritional information and sensory evaluation.

\section{Commercial viability of the modified product}

Target manufacturing bulk was achieved, and surface colour was consistent with the standard biscuit.

Biscuit bases were also checked against the standard product for hardness, using a Stevens Texture Analyser, and no differences were recorded. Results of vitamin analysis and nutritional information are detailed in Table 1.

\section{Discussion}

Biscuits are typically high in both fat and sugar and have been identified as a food contributing to negative health [1]. It has been recommended that the intake of biscuits and related products should be reduced $[4,11]$. This study concentrated on one of the best selling biscuits in the UK that is consumed regularly by both children and adults. An essential part of this study was the maintenance of commercial and consumer viability, i.e. the final product had to be produced using commercial parameters, and had to be acceptable to the consumer in terms of organoleptic properties. Reducing the materials that were thought to be essential in the standard product was difficult. The complex interaction between these raw materials necessitated a large number of formulation modifications, resulting in complicated manufacturing issues. For example, reduction in fat resulted in several undesirable effects such as toughening of base dough, shrinkage of final product, loss of colour and eating quality. Addressing one problem often created another.

\section{Biscuit dough}

It was clear that dough's produced under laboratory conditions were significantly different when produced commercially. Specifically, dough water levels needed to be higher in the laboratory than on plant in order to facilitate processing by hand. Plant processed dough's needed to be drier to facilitate extraction from the rotary moulder. Benefits of reduced recipe water required for commercially processing biscuits include reduced hydration of flour proteins (less toughness of the dough) and less water to remove during baking in order to achieve the required moisture levels. It was clear that in order to maintain workable dough following fat reduction, that an increase in water was needed. Fat makes a significant contribution to dough consistency, with dough's becoming less short (tougher) with reduced recipe fat. This resulted in greater shrinkage during baking when the two biscuits were compared. The most important function of fat in biscuit dough is the prevention of gluten development which enhances eating quality [33]. Reduction in fat also resulted in the need to alter baking conditions in order to maintain a desirable product colour. This was achieved by increasing baking time and/or temperature. As a result of this, the eating characteristics of the product became very tough and could not be described as "melt-in-the-mouth". To reduce this toughening effect, dilution of flour proteins by the substitution of a portion of the flour with heat treated flour was made.

\section{Baking process and the modified product}

During heat treatment, the flour proteins have been denatured and therefore unable to produce gluten. In this way, an original gluten forming protein content of $9 \%$ was reduced to $4.5 \%$. In addition, the use of emulsifier extended the functionality of the available fat. A modification in the mixing parameters was also made to reduce the toughening during the mixing phase. The combination of these modifications contributed to the viability of the final product. Reducing fat facilitated a reduction in energy equivalent to $9 \mathrm{kcal}$ per gram.

An important feature of the modified product was a reduction in calories. Sugar (sucrose), traditionally referred to as an essential ingredient in biscuit manufacture, performs several functions, including sweetness, product spread, product colour and eating quality [33]. As sugar levels were decreased, not surprisingly sweetness was reduced because of the decreased sweetness of the sugar 
substitute used in the modified biscuit. Colour during thermal processing was also reduced and the product became less palatable by loosing its desirable snap or crunch. Like fat reduction, addressing the problems associated with sugar reduction required a complex combination of modifications. Sugar is a bulky raw material and simply removing it, or reducing it from the formulation had the effect of increasing final fat levels. A substitute bulking-ingredient was therefore required, and a mix of polydextrose and fructo-oligosaccharide was found to provide the best results. Of importance here, was the contribution these materials made to further reducing the energy content of the biscuit. Sugar contributes 4 kcal per gram, whilst polydextrose contributes $1 \mathrm{kcal}$ per gram and fructo-oligosaccharide contributes $2 \mathrm{kcal}$ per gram. The addition of both polydextrose and fructo-oligosaccharide made possible the removal of all the sugar in the original biscuit base. In addition, fructo-oligosaccharide is a prebiotic fibre, and is reported to improve gut health $[20,21]$. Product sweetness was enhanced by the use of a heat-stable synthetic sweetener (acesulfame K). Product spread and eating quality was improved by increasing the concentration of aerating agent. This had the effect of opening the structure thereby yielding a more palatable product. The required enhancement of surface colour was made possible with the addition of whey powder, which contributes the raw materials required for Maillard Reactions (reducing sugars and amino acids). Maillard Reactions are known to contribute to the surface or crust colour of many baked items. The complete removal of sodium chloride from the formulation presented no problems with respect to dough or product viability. However, sodium is a part of the aerating agent (sodium bicarbonate) hence a small level was present in the final product.

\section{Modified product functionality}

Vitamins $\mathrm{B}_{6}, \mathrm{~B}_{12}$ and folic acid were added because of their association with serum homocysteine. Homocysteine is associated with increased risk of CHD $[23,24,29,31]$. Vitamin $\mathrm{C}$ is very heat sensitive, and is known to degrade during thermal processing. It was therefore necessary to use an encapsulated form in order to offer protection during this phase of processing. Difficulty was encountered in establishing levels for addition to the base dough that would deliver the required dosage on consumption of the biscuits. Specifically, folic acid was found to be remarkably heat stable. The very low levels needed for the commercial trials necessitated careful handling on plant, particularly ensuring even distribution during the limited mixing phase. Converting the information gathered in the laboratory to a commercially viable manufacturing experience was not straightforward. Development of the biscuit in the laboratory was completed by hand. In this way, softer dough's than those processed on plant had to be used. This gave "false" information, e.g. the extra water needed to produce the softer dough's was misleading due to increased protein hydration.

In addition, the relative gentle action of hand processing compared to the high forces encountered during rotary moulding, allowed the processing of dough's that could not be processed under commercial conditions. However, laboratory based development did confirm associations between ingredients that proved invaluable. For example, the relationship between dough water and fat levels. Translating the lab-based modifications to the biscuit formulation to commercial manufacture proved difficult initially. Though the dough was dry and crumbly it rotary moulded well giving good extraction. In-weights were quickly achieved, with no tearing of the bases. Final product parameters were in place, including product bulk and moisture levels. The biscuit bases were successfully jammed ready for wrapping. Analysis of the product showed desired levels of all vitamins.

In addition, a reduction in energy from $448 \mathrm{kcal}$ per 100 $\mathrm{g}$ to $396 \mathrm{kcal}$ per $100 \mathrm{~g}$ was achieved. Even with standard jam (a requirement of the company) the total sugar content was reduced from $32.5 \%$ to $22.5 \%$. This sugar content in the biscuit came from the jam only, as the sugar in the base had been completely removed. Total fat was reduced from $16.7 \%$ to $7 \%$ and sodium was halved, from $0.2 \%$ to $0.1 \%$. The formulation used in this study was successful in terms of suitability for commercial process parameters. Problem-free dough extraction through the rotary moulder, is crucial for commercial viability. All product quality requirements were achieved, i.e. surface colour, bulk, spread, and weight. Secondary processing highlighted no problems and the product was wrapped using standard product outputs. The findings from this study are consistent with previously published work on effects of ingredient levels [33-35]. With no sucrose in the base recipe, caramelisation reactions during the baking phase were insufficient to give the desired colour to the biscuit surface. Addition of whey powder has long been used in the food industry to enhance crust colour of a variety of baked products including biscuits, and the improvements to surface colour in this study are consistent with those of others [33].

Dough consistency has also been shown to be crucial in the successful manufacture of rotary moulded biscuits. This study has shown that a significant reduction in dough water is required for operational success under commercial manufacturing conditions. Normally, soft dough's tend to give "tails" (distortion of the dough piece following extraction) when rotary moulded, particularly when they contain high fat levels [36]. In this study however, the dough contains very little fat, so any dough that 
was considered too soft must have contained high levels of water.

In this study, a healthy biscuit was successfully produced under strict commercial manufacturing conditions, and furthermore the biscuit was acceptable to the consumer. The findings of this study confirmed that traditional highfat and high-sugar biscuits which are not associated with healthy diets by most consumers can be modified to produce a healthy alternative and can be manufactured under strict commercial conditions. At a time when obesity is a major concern in the UK, and foods high in energy and low in nutrients are linked to the causes of obesity and negative health, the manufacturers of these products are under increasing pressure to produce healthy alternatives. Such developments across a range of products will have a profound affect on the food industry as children and adults alike are becoming increasingly aware of the need to consume a health promoting diet.

\section{Conclusion}

This study has confirmed that traditional high-fat and high-sugar biscuits which are not associated with healthy diets by most consumers can be modified. This modification procedure was performed by the addition of vitamin $\mathrm{B}_{6}$, vitamin $\mathrm{B}_{12}$, Folic Acid, Vitamin $\mathrm{C}$ and Prebiotic fibre, while reducing salt and sugar, thereby converting a traditional food product into a functional one. This resulted in a healthy alternative that is not only acceptable to consumers, but can be manufactured under strict commercial conditions.

\section{Authors' contributions}

Dr Wyndhan Boobier designed the modified biscuit. Dr Julien Steven Baker and Professor Bruce Davies made substantial contribution to study design, conception of data and data analysis and interpretation. Boobier, Baker and Davies gave final manuscript approval.

\section{References}

I. Department of Health and Social Services: Nutritional aspects of cardiovascular disease, report on health and social subjects Volume 46. London HMSO; 1995:2-5.

2. O'Connor M: Europe and Nutrition. Brit Med J 1992, 304: $178-182$.

3. LaRosa JC, Hunninghake D, Bush D, Criqui MH, Getz GS, Gollo AM, Grundy SM, Rakita L, Robertson RM, Weisfeldt ML, Cleeman Jl: The Cholesterol Facts. A summary of the evidence relating dietary fats, serum cholesterol and coronary heart disease. Circulation 1990, 81 : 1721-1733.

4. Adachi $\mathrm{H}$, Hino $\mathrm{A}$ : Trends in nutritional intake and serum cholesterol levels over $\mathbf{4 0}$ years in Tanushimaru, Japanese men. J of Epid 2005, I 5:85-9.

5. Mensink RP, Katan MB: Effect of monounsaturated fatty acids versus complex carbohydrates on high-density lipoproteins in healthy men and women. Lancet 1987, I(8525): 122-125.

6. Pietinen $P$, Rimm EB, Korhonen $P$ : Intake of dietary fibre and risk of coronary heart disease in a cohort of Finnish men. The Alpha-Tocopherol Beta-Carotene Prevention Study. Circulation 1996, 94:2720-7.
7. He J, Ogden LG, Vupputuri S, Bazzano L, Loria C, Whelton PK: Dietary sodium intake and myocardial infarction. J of the Amer Med Assoc 1999, 282:2027-34.

8. MacDonald I, Braithwaite DM: The influence of dietary carbohydrates on the lipid patterns in serum and in adipose tissue. Clin Sci 1964, 27:23-30.

9. Couch SC, Daniels SR: Diet and blood pressure in children. Curr Opin in Pedi 2005, 7:642-7.

10. Nisbett EF, Rossiter AH, Miller AR, Thacker D: Fat in short dough biscuits. Flour Milling and Baking Research Association Bulletin (FMBRA) 1986, 2:63-77.

11. Ashwell MA: Diet and heart disease - A Round Table of Factors. British Nutrition Foundation. London; 1993:19-23.

12. Willet WC, Stampfer MJ, Manson JE: Intake of Tran's fatty acids and risk of coronary heart disease among women. Lancet 1993, 341:58I-5.

13. Gibson GR, Williams MW: Functional Foods. Concept to Product 2000:17-26.

14. Kapoor R, Metzger LE: Small-scale manufacture of process cheese using a rapid visco analyzer. J of Dair Sci 2005, 10:3382-91.

15. Kubomara K: Japan redefines functional foods. Prepared Foods 1998, 167:129-132.

16. Hume R, Weyers E, Rowan T, Reia DS, Hillis WS: Leucocyte ascorbic acid levels and acute myocardial infarction. Brit Heart J 1972, 34:238-43.

17. Machtey I, Syrkis I, Fried M: Studies of blood ascorbic acid levels in acute myocardial infarctions. Inter J of Clin Chem and Appl Mol Biol 1975, 62:|49-5|.

18. Jaxa-Chamiec T, Bednarz B, Drozdowska D, Gessek J, Gniot J, Janik K, Kaka-Urbanek T, Maciejewski P, Ogorek M, Szpajer M: MIVIT Trial Group. Antioxidant effects of combined vitamins $C$ and $E$ in acute myocardial infarction. The randomized, doubleblind, placebo controlled, multicenter pilotMyocardial Infarction and Vitamins (MIVIT) trial. Kardiology Poland 2005, 62:344-50.

19. Department of Health Report on Health and Social Science: Dietary Reference Values for Food, Energy and Nutrients for the United Kingdom. 1999, 41:37-43.

20. Gibson GR, Roberfroid MB: Dietary modulation of the human colonic microbiota: introducing the concept of prebiotics. J of Nutr 1995, I 25: I 40 I-12.

21. Ried K: Gastrointestinal health: The role of pro- and pre-biotics in standard foods. Aust Fam Phys 2004, 33:253-5.

22. Bender DA: Oestrogens and vitamin $\mathbf{B}_{6}-$ actions and interactions. World rev of nutr and diet 1987, $51: 140-188$.

23. Bender DA: Vitamin B6 requirements and recommendations. Euro J of Clin Nutr 1989, 43:289-309.

24. Selhub J, Jacques PF, Wilson WF, Rush D, Resenburgh IH: Vitamin status and intake of primary determinants of homocysteinemia in an elderly population. J of the Amer Med Assoc 1993, 270:2693-2698.

25. Jacob RA, Wu MM, Hennings SM, Swendseid ME: Homocysteine increases as folate decreases in plasma of healthy young men during short-term folate and methyl group restriction. J of Nutr 1994, 7:1072-1080.

26. McCully KS: Vascular pathology of homocysteinemia: Implications for the pathogenesis of arteriosclerosis. Amer $J$ of Path 1969, 56: III-28.

27. Urgert R, Van Vliet T, Zock PL, Katan MB: Heavy coffee consumption and plasma homocysteine: a randomised controlled trial in healthy volunteers. Amer J of Clin Nutr 2000, 5: I I 07-I I I 0.

28. Ueland P, Refsum H, Beresford SA, Vollset SE: The controversy over homocysteine and cardiovascular risk. Amer J of Clin Nutr 2000, 2:324-332.

29. Liem A, Reynierse-Buitenwerf GH, Zwinderman AH, Jukema JW, van Veldhuisen DJ: Secondary prevention with folic acid: results of the Goes extension study. Heart 2005, I: I 1 13-4.

30. Eichner ER, Hillman RS: The evolution of anaemia in alcoholic patients. Amer J of Med 197I, 50:2I8-232.

31. Morrison HI, Schaubel D, Desmeules M: Serum folate and risk of coronary heart disease. J of the Amer Med Assoc 1996, 275: 1893-1896.

32. Scott JM, Weir DG, Kirke PN: Prevention of neural tube defects with folic acid: a success but... Quar J of Med 1994, 87:705-707. 
33. Lawson R, Miller AR, Thacker D: Rotary moulded short dough biscuits: Part I I. The effects of the level of ingredients on the properties of Lincoln biscuits. Flour Milling and Baking Research Association Report (FMBRA) 198I, 93:15-20.

34. Miller AR, Thacker D, Turrell SG: Performance of single wheat flours in a small-scale baking test for semi-sweet biscuits. Flour Milling and Baking Research Association Report (FMBRA) 1986, 123:17-24.

35. Fearn T, Miller AR, Thacker D: Rotary moulded short dough biscuits Part I I : The effects of flour characteristics and recipe water level on the properties of Lincoln biscuits. Flour Milling and Baking Research Association Report (FMBRA) 1983, 102:8-12.

36. Lawson R, Miller AR, Thacker $D$ : Rotary moulded short-dough biscuits Part IV. The effects of rotary moulder control settings on the properties of Lincoln biscuits. Flour Milling and Baking Research Association Report (FMBRA) 1983, 106:9-17.

Publish with Bio Med Central and every scientist can read your work free of charge

"BioMed Central will be the most significant development for disseminating the results of biomedical research in our lifetime. "

Sir Paul Nurse, Cancer Research UK

Your research papers will be:

- available free of charge to the entire biomedical community

- peer reviewed and published immediately upon acceptance

- cited in PubMed and archived on PubMed Central

- yours - you keep the copyright

Submit your manuscript here:

http://www.biomedcentral.com/info/publishing_adv.asp 